\title{
Modelling and Small-Signal Analysis of a Grid Connected Doubly-Fed Induction Generator
}

\author{
Francoise Mei, Student Member, IEEE, and Bikash C. Pal, Senior Member, IEEE
}

\begin{abstract}
This paper describes the modeling and small signal analysis of a grid connected doubly-fed induction generator (DFIG). Different models are formulated and compared with each other for different assumptions (two or one-mass drive train, with or without stator transients). The models are developed from the basic flux linkage, voltage and torque equations. Eigenvalues and participation factor analysis of the linearized models. are carried out to relate the DFIG electromechanical modes to its relevant state variables.
\end{abstract}

Index Terms-doubly-fed induction generator, non-linear dynamical model, small-signal model, eigenvalue analysis.

\section{INTRODUCTION}

$\mathrm{W}$ ITH the worldwide trend and wish to integrate more wind energy into the power system, there has been an urgent need of suitable dynamical models of wind generators. For the doubly-fed induction generator (DFIG), this resulted in many papers (e.g. [1]-[5]) presenting, in most cases, nonlinear dynamical models.

As control design is a major concern, a small-signal analysis can give valuable information on the DFIG properties, limitations and control options. This paper presents the small-signal analysis of a grid connected DFIG. To this end, the system non-linear dynamical model is derived. Then, its linearization and eigenvalue analysis are presented.

In section II, the phase voltage equations of the DFIG are formulated. In sections III-IV, the dq-transformation used in this paper is specified and a dq-model for stability studies is obtained. In sections V-VII, the electromagnetic torque derivation, drive train and converter models are presented. In section VIII, the power flow equations are established to complete the system mathematical model. In section IX, different models are formulated for different sets of assumptions. Finally, in section X, the models are compared with each other with the results of their eigenvalue analysis.

\section{DFIG EQUATIONS IN abc-FORM}

The convention adopted in this paper for positive current, voltage and flux directions is shown in Fig. 1. As the machine

This work is supported by the EPSRC under Grant GR/S28082/01.

The authors are with the Department of Electrical Engineering, Imperial College London, SW72AZ London, UK (e-mails: francoise.mei@imperial.ac.uk, b.pal@imperial.ac.uk). is working in generator mode, positive currents are flowing out of it.

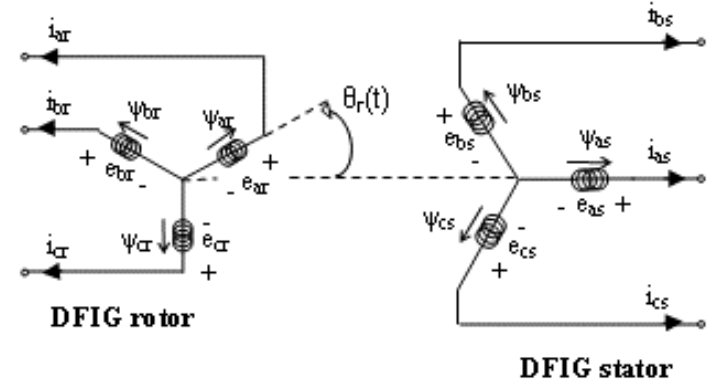

Fig. 1. Definition of positive current, voltage and flux directions.

The sign of the self-flux linkage produced by a current in a circuit is the same as that of the current. The polarity of the voltage induced by a changing flux is so that it results in a current that opposes the change (Lenz's law).

Applying the Kirchoff voltage law to Fig. 1 gives:

$$
v_{a s}=-\frac{1}{\omega_{B}} \frac{d}{d t} \psi_{a s}-R_{s} i_{a s}
$$

where $\mathrm{R}_{\mathrm{s}}, \mathrm{v}_{\mathrm{as}}, \mathrm{i}_{\mathrm{as}}$, and $\psi_{\text {as }}$ are in [pu] and are the stator phase-a winding resistance, voltage, current and flux linkage, respectively; $\omega_{\mathrm{B}}[\mathrm{rad} / \mathrm{sec}]$ is the system base frequency which is equal to the synchronous frequency, i.e. $\omega_{\mathrm{B}}=2 \pi \mathrm{f}$; and $\mathrm{t}$ is the time in [sec]. In (1), the flux $\psi_{\text {as }}$ is:

$$
\begin{gathered}
\psi_{a s}=\left(L_{\text {self }, s}+L_{\text {leak }, s}\right) i_{a s}+L_{m u t, s}\left(i_{b s}+i_{c s}\right)+\ldots \\
L_{s r}\left(\cos \theta_{r} i_{a r}+\cos \left(\theta_{r}+\frac{2 \pi}{3}\right) i_{b r}+\cos \left(\theta_{r}-\frac{2 \pi}{3}\right) i_{c r}\right)(2)
\end{gathered}
$$

where $\theta_{\mathrm{r}}=\theta_{\mathrm{r}}(\mathrm{t})$ is the angle between the stator a-axis (stationary) and rotor a-axis (rotationary) as shown on Fig. 1; $\mathrm{L}_{\text {selff,s }}$ and $\mathrm{L}_{\text {leak,s }}$ are the self- and leakage inductance of a stator winding, respectively; $\mathrm{L}_{\text {mut.s }}$ is the mutual inductance between two stator windings; and $\mathrm{L}_{\mathrm{sr}}$ is the peak value of the mutual inductance between stator and rotor windings. For the other phases of the stator and rotor, similar equations can be written. 


\section{III. abc-dq TRANSFORMATION}

\section{A. Transformation Matrix}

For easier control, three-phase variables are transformed into dq-variables. In matrix notation, we have:

$$
v_{q d_{0}}=T_{\theta} v_{a b c}
$$

where $\mathrm{v}_{\mathrm{qd} 0}=\left[\begin{array}{lll}\mathrm{v}_{\mathrm{q}} & \mathrm{v}_{\mathrm{d}} & \mathrm{v}_{0}\end{array}\right]^{\prime}, \mathrm{v}_{\mathrm{abc}}=\left[\begin{array}{lll}\mathrm{v}_{\mathrm{a}} & \mathrm{v}_{\mathrm{b}} & \mathrm{v}_{\mathrm{c}}\end{array}\right]^{\prime}$, and $\mathrm{T}_{\theta}$ is the abc-to$\mathrm{dq}$ transformation matrix. In this paper, the power invariant transformation is chosen, and the d-axis is leading the q-axis (IEEE recommendation for synchronous machines [9]). Fig. 2 shows the dq-frame with respect to the stator 3-axis frame. The corresponding transformation matrix is given in (4).

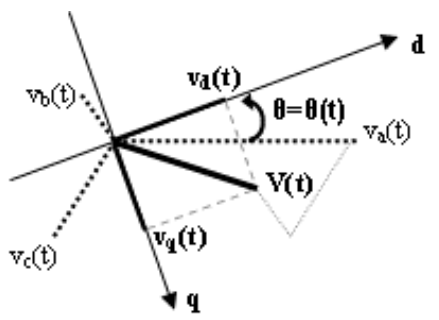

Fig.2. dq-frame with respect to stator abc-frame.

$$
T_{\theta}=\sqrt{\frac{2}{3}} \cdot\left(\begin{array}{ccc}
\sin \theta & \sin (\theta-2 \pi / 3) & \sin (\theta+2 \pi / 3) \\
\cos \theta & \cos (\theta-2 \pi / 3) & \cos (\theta+2 \pi / 3) \\
1 / \sqrt{2} & 1 / \sqrt{2} & 1 / \sqrt{2}
\end{array}\right)
$$

$\mathrm{T}_{\theta}$ is orthogonal, thus the inverse transformation matrix is the transpose of $\mathrm{T}_{\theta}$.

\section{B. DFIG Equations in dq-Form}

Applying (4) to (1)-(2) and the other stator and rotor phase equations gives the DFIG dq-model in [pu]:

$$
\begin{aligned}
v_{q s} & =-\frac{1}{\omega_{B}} \frac{d}{d t} \psi_{q s}-R_{s} i_{q s}+\omega \psi_{d s} \\
v_{d s} & =-\frac{1}{\omega_{B}} \frac{d}{d t} \psi_{d s}-R_{s} i_{d s}-\omega \psi_{q s} \\
v_{q r} & =-\frac{1}{\omega_{B}} \frac{d}{d t} \psi_{q r}-R_{r} i_{q r}+\left(\omega-\omega_{r}\right) \psi_{d r} \\
v_{d r} & =-\frac{1}{\omega_{B}} \frac{d}{d t} \psi_{d r}-R_{r} i_{q r}-\left(\omega-\omega_{r}\right) \psi_{q r} \\
\psi_{q s} & =L_{s s} i_{q s}+L_{m} i_{q r} \\
\psi_{d s} & =L_{s s} i_{d s}+L_{m} i_{d r} \\
\psi_{q r} & =L_{r r} i_{q r}+L_{m} i_{q s} \\
\psi_{d r} & =L_{r r} i_{d r}+L_{m} i_{d s}
\end{aligned}
$$

In (5)-(8), $\omega$ is the rotational speed of the dq-frame, i.e. $\omega=d \theta / d t$ where $\theta=\theta(t)$ is the angle between the d-axis and stator a-axis (Fig. 2); and $\omega_{\mathrm{r}}$ is the rotational speed of the rotor, i.e. $\omega_{\mathrm{r}}=\mathrm{d} \theta_{\mathrm{r}} / \mathrm{dt}$. For the synchronously rotating frame, $\omega$ is the synchronous speed, thus in $[\mathrm{pu}] \omega=\omega_{\mathrm{s}}=1$ and $\left(\omega-\omega_{\mathrm{r}}\right)$ $=\left(\omega_{\mathrm{s}}-\omega_{\mathrm{r}}\right)=\mathrm{s} \omega_{\mathrm{s}}$ where $\mathrm{s}$ is the slip. In (9)-(12), $\mathrm{L}_{\mathrm{ss}}=$ $\mathrm{L}_{\text {self,s }}+\mathrm{L}_{\text {leak }, \mathrm{s}}-\mathrm{L}_{\mathrm{mut}, \mathrm{s}}$ and $\mathrm{L}_{\mathrm{m}}=\mathrm{L}_{\mathrm{sr}}$.

\section{DFIG dq-EQuATIONS FOR STABILITY STUDIES}

In stability studies, machines are usually represented as a voltage source behind transient impedance. Equations (5)-(12) can be rewritten so that the DFIG is represented as shown in Fig. 3. To this end, stator and rotor fluxes in (5)-(8) are eliminated with (9)-(12), and the following new variables are defined:

$$
\begin{aligned}
& v_{q}^{\prime}=\left(L_{m} / L_{r r}\right) \omega_{s} \psi_{d r} \\
& v_{d}^{\prime}=-\left(L_{m} / L_{r r}\right) \omega_{s} \psi_{q r} \\
& X_{s}^{\prime}=\omega_{s}\left(L_{s s} L_{r r}-L_{m}^{2}\right) / L_{r r} \\
& T_{0}^{\prime}=\omega_{s} L_{r r} / R_{r}
\end{aligned}
$$

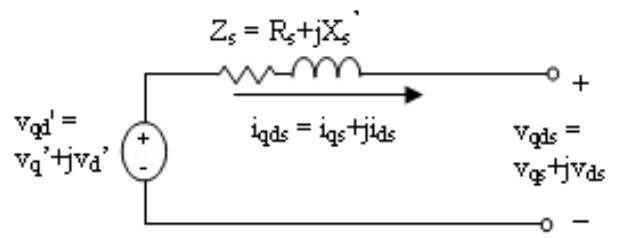

Fig. 3. DFIG model for stability studies.

After some substitutions, the DFIG-model in [pu] becomes:

$$
\begin{aligned}
& \frac{X_{S}^{\prime}}{\omega_{S} \omega_{B}} \frac{d}{d t} i_{q s}=-\left(R_{S}+\frac{X_{S}-X_{S}^{\prime}}{T_{0}^{\prime}}\right) i_{q s}+X_{s}^{\prime} i_{d s} \ldots \\
& +(1-s) v_{q}^{\prime}-\frac{1}{T_{0}^{\prime}} v_{d}^{\prime}-v_{q s}+\frac{L_{m}}{L_{r r}} v_{q r} \\
& \frac{X_{s}^{\prime}}{\omega_{s} \omega_{B}} \frac{d}{d t} i_{d s}=-X_{s}^{\prime} i_{q s}-\left(R_{S}+\frac{X_{s}-X_{S}^{\prime}}{T_{0}^{\prime}}\right) i_{d s} \ldots \\
& +\frac{1}{T_{0}^{\prime}} v_{q}^{\prime}+(1-s) v_{d}^{\prime}-v_{d s}+\frac{L_{m}}{L_{r r}} v_{d r} \\
& \frac{1}{\omega_{s} \omega_{B}} \frac{d}{d t} v_{q}^{\prime}=\frac{X_{s}-X_{s}^{\prime}}{T_{0}^{\prime}} i_{d s}-\frac{1}{T_{0}^{\prime}} v_{q}^{\prime}+s v_{d}^{\prime}-\frac{L_{m}}{L_{r r}} v_{d r} \\
& \frac{1}{\omega_{s} \omega_{B}} \frac{d}{d t} v_{d}^{\prime}=-\frac{X_{s}-X_{s}^{\prime}}{T_{0}^{\prime}} i_{q s}-s v_{q}^{\prime}-\frac{1}{T_{0}^{\prime}} v_{d}^{\prime}+\frac{L_{m}}{L_{r r}} v_{q r} \\
& i_{q r}=-\left(1 / \omega_{s} L_{m}\right) v_{d}^{\prime}-\left(L_{m} / L_{r r}\right) i_{q s} \\
& i_{d r}=\left(1 / \omega_{s} L_{m}\right) v_{q}^{\prime}-\left(L_{m} / L_{r r}\right) i_{d s} \\
& \psi_{q s}=-\left(1 / \omega_{s}\right) v_{d}^{\prime}+\left(X_{s}^{\prime} / \omega_{s}\right) i_{q s} \\
& \psi_{d s}=\left(1 / \omega_{s}\right) v_{q}^{\prime}+\left(X_{s}^{\prime} / \omega_{s}\right) i_{d s}
\end{aligned}
$$




\section{Electromagnetic TORQUe}

The instantaneous total active power produced by the DFIG is the sum of stator and rotor active powers:

$$
P_{D F I G}=P_{S}+P_{r}
$$

where $\mathrm{P}_{\mathrm{s}}$ and $\mathrm{P}_{\mathrm{r}}$ are the real parts of $\mathrm{v}_{\mathrm{qds}} \cdot \mathrm{i}_{\mathrm{qds}}{ }^{*}$ and $\mathrm{v}_{\mathrm{qdr}} \cdot \mathrm{i}_{\mathrm{qdr}}{ }^{*}$ respectively. With $\mathrm{v}_{\mathrm{qds}}=\mathrm{v}_{\mathrm{qs}}+\mathrm{jv}_{\mathrm{ds}}, \mathrm{i}_{\mathrm{qds}}=\mathrm{i}_{\mathrm{qs}}+\mathrm{ji}_{\mathrm{ds}}, \mathrm{v}_{\mathrm{qdr}}=\mathrm{v}_{\mathrm{qr}}+\mathrm{j} \mathrm{v}_{\mathrm{dr}}$ and $\mathrm{i}_{\mathrm{qdr}}=\mathrm{i}_{\mathrm{qr}}+\mathrm{ji}_{\mathrm{dr}}$, we have:

$$
\begin{aligned}
& P_{s}=v_{q s} i_{q s}+v_{d s} i_{d s} \\
& P_{r}=v_{q r} i_{d r}+v_{d r} i_{d r}
\end{aligned}
$$

Substituting (5)-(8) in (26)-(27), gives:

$$
\begin{aligned}
P_{D F I G} & =-R_{s}\left(i_{q s}^{2}+i_{d s}^{2}\right)-R_{r}\left(i_{\left.q r^{2}+i_{d r}{ }^{2}\right) \ldots}\right. \\
& -i_{q s} \frac{1}{\omega_{B}} \frac{d \psi_{q s}}{d t}-i_{d s} \frac{1}{\omega_{B}} \frac{d \psi_{d s}}{d t} \ldots \\
& -i_{q r} \frac{1}{\omega_{B}} \frac{d \psi_{q r}}{d t}-i_{d r} \frac{1}{\omega_{B}} \frac{d \psi_{d r}}{d t} \ldots \\
+\omega_{s} \psi_{d s} i_{q s} & -\omega_{s} \psi_{q s} i_{d s}+s \omega_{s} \psi_{d r} i_{q r}-s \omega_{s} \psi_{q r} i_{d r}
\end{aligned}
$$

The first two terms correspond to the machine losses, the second four terms to the power associated with flux variation, and the last four terms to the airgap power, i.e. the power converted from mechanical to electrical form. The electromagnetic torque $T_{e}$ is obtained by dividing the airgap power by the mechanical speed of the DFIG rotor. Doing this and using (9)-(12), gives in [pu]:

$$
T_{e}=L_{m}\left(i_{q s} i_{d r}-i_{d s} i_{q r}\right)
$$

Adding and subtracting the term $\left(\mathrm{L}_{\mathrm{m}} \mathrm{L}_{\mathrm{rr}} / \mathrm{L}_{\mathrm{rr}}\right) \mathrm{i}_{\mathrm{qs}} \mathrm{i}_{\mathrm{ds}}$ gives the expression of $\mathrm{T}_{\mathrm{e}}[\mathrm{pu}$ to be used with the DFIG model (5)(12):

$$
T_{e}=\left(L_{m} / L_{r r}\right)\left(i_{q s} \psi_{d r}-i_{d s} \psi_{q r}\right)
$$

Substituting (13)-(14) in (30) gives another equivalent expression of $\mathrm{T}_{\mathrm{e}}$ to be used with the DFIG model (17)-(24):

$$
T_{e}=\left(v_{d}^{\prime} / \omega_{s}\right) i_{d s}+\left(v_{q}^{\prime} / \omega_{s}\right) i_{q s}
$$

\section{DRIVE TRAIN MODEL}

\section{A. Two-Mass Model}

If the turbine, gearbox, generator, shafts and other transmission components are modeled as two masses $\mathrm{H}_{\mathrm{t}}$ and $\mathrm{H}_{\mathrm{g}}$ (with $\mathrm{H}_{\mathrm{t}}>\mathrm{H}_{\mathrm{g}}$ ) at the extremities of an equivalent common shaft, it follows from mechanics theory, that:

$$
\begin{aligned}
& 2 H_{t} \frac{d \omega_{t}}{d t}=T_{m}-T_{s h} \\
& 2 H_{g} \frac{d \omega_{r}}{d t}=T_{s h}-T_{e} \\
& \frac{d \theta_{t w}}{d t}=\left(\omega_{t}-\omega_{r}\right) \omega_{B}
\end{aligned}
$$

where $\mathrm{H}_{\mathrm{t}}$ and $\mathrm{H}_{\mathrm{g}}$ [s] are the turbine and generator inertia, $\omega_{\mathrm{t}}$ and $\omega_{\mathrm{r}}[\mathrm{pu}]$ are the turbine and DFIG rotor speed, and $\mathrm{T}_{\mathrm{sh}}[\mathrm{pu}]$ is the shaft torque:

$$
T_{s h}=K \theta_{t w}+D \frac{d \theta_{t w}}{d t}
$$

In (35), $\theta_{\mathrm{tw}}[\mathrm{rad}]$ is the shaft twist angle, $\mathrm{K}[\mathrm{pu} / \mathrm{rad}]$ the shaft stiffness, and D [pu.s/rad] the damping coefficient.

Substituting (35) in (32)-(33), and recalling $\omega_{\mathrm{r}}=(1-\mathrm{s}) \omega_{\mathrm{s}}$, gives the drive train 2-mass model:

$$
\begin{aligned}
& 2 H_{t} \frac{d \omega_{t}}{d t}=T_{m}-\left(K \theta_{t w}+D\left(\omega_{t}-(1-s) \omega_{s}\right) \omega_{B}\right) \\
& -2 H_{g} \omega_{s} \frac{d s}{d t}=\left(K \theta_{t w}+D\left(\omega_{t}-(1-s) \omega_{s}\right) \omega_{B}\right)-T_{e} \\
& \frac{d \theta_{t w}}{d t}=\left(\omega_{t}-(1-s) \omega_{s}\right) \omega_{B}
\end{aligned}
$$

where $\mathrm{T}_{\mathrm{e}}$ is given in (31).

\section{B. One-Mass Model}

If the turbine, gearbox, shafts and generator are lumped together into an equivalent mass $\mathrm{H}_{\text {tot }}$ [s], the following swing equation in $[\mathrm{pu}]$ models the drive train:

$$
-2 H_{t o t} \omega_{s} \frac{d s}{d t}=T_{m}-T_{e}
$$

where $T_{e}$ is given in (31).

\section{CONVERTER MODEL}

In this paper, the converter connected between the DFIG rotor and the grid consists of two PWM voltage source inverters (VSI) separated by a dc-link as shown on Fig. 4. The grid side converter varies its modulation index $\mathrm{m}_{2}$ in order to maintain the dc-voltage $\mathrm{V}_{\mathrm{dc}}$ constant and operates at unity power factor, i.e. only the stator delivers the required reactive power to maintain the terminal voltage (stator voltage); the rotor side converter injects the appropriate rotor voltage so that the DFIG speed is equal to its reference value (determined so that the DFIG extracts the maximum amount of wind power within the limit of the machine). The converters are considered as lossless devices, and the switching dynamics are not modeled since their frequency range is much higher than that of interest in power system stability studies. 


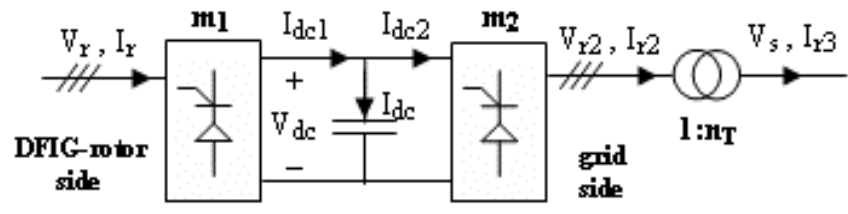

Fig. 4. Back-to-back converter between DFIG rotor and grid. $\mathrm{m}_{1}$ and $\mathrm{m}_{2}$ are modulation index.

In most papers, the dc-link capacitor dynamic is not represented and $\mathrm{V}_{\mathrm{dc}}$ is assumed as constant. Here, as verification, the differential equation of the dc-capacitor is added to the DFIG model.

To this end, we first establish the relations between ac- and dc-variables of the PWM-VSI shown in Fig. 5. In actual unit, we have [6]:

$$
V_{\text {LNrms }}=(1 / 2 \sqrt{2}) m V_{D C}
$$

where $\mathrm{V}_{\mathrm{LNrms}}[\mathrm{V}]$ is the ac line-to-neutral rms voltage, $\mathrm{m}$ the amplitude modulation ratio, and $\mathrm{V}_{\mathrm{DC}}[\mathrm{V}]$ the dc voltage. The power balance between ac- and dc-sides gives in [VA]:

$$
3 V_{\text {LNrms }} I_{r m s}=V_{D C} I_{D C}
$$

where $I_{r m s}[A]$ is the ac rms current, and $I_{D C}[A]$ the average dc current. Substituting (40) in (41) gives:

$$
I_{D C}=(3 / 2 \sqrt{2}) m I_{r m s}
$$

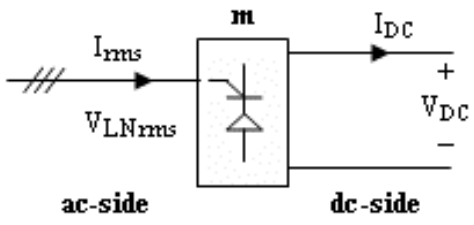

Fig. 5. PWM-VSI with amplitude modulation index $\mathrm{m}$.

In the previous sections the DFIG equations were derived in [pu], thus let us adopt a [pu] notation for the converter equations by defining:

$$
\begin{aligned}
V_{d c} & =\frac{V_{D C}}{2 \sqrt{2} V_{\text {base }, 1 p h}} \\
I_{d c} & =\frac{3 I_{D C}}{2 \sqrt{2} I_{\text {base }}}
\end{aligned}
$$

where $V_{d c}$ and $I_{d c}$ are in [pu], $V_{\text {base,1ph }}$ and $I_{\text {base }}$ are the 1-phase base voltage and base current of the DFIG. Thus, for Fig. 4 the following equations in [pu] hold:

$$
V_{r}=m_{1} V_{d c}
$$

$$
\begin{aligned}
& V_{r 2}=m_{2} V_{d c} \\
& I_{d c 1}=m_{1} I_{r} \\
& I_{d c 2}=m_{2} I_{r 2}
\end{aligned}
$$

The differential equation of the dc-link capacitor is:

$$
I_{d c}=I_{d c 1}-I_{d c 2}=C \frac{d V_{d c}}{d t}
$$

With (45)-(48), (49) becomes:

$$
I_{d c}=\frac{1}{V_{d c}}\left(V_{r} I_{r}-V_{r 2} I_{r 2}\right)=C \frac{d V_{C}}{d t}
$$

Since $V_{\mathrm{s}}=\mathrm{n}_{\mathrm{T}} \mathrm{V}_{\mathrm{r} 2}$ and $\mathrm{I}_{\mathrm{r} 3}=\mathrm{I}_{\mathrm{r} 2} / \mathrm{n}_{\mathrm{T}}$, where $\mathrm{n}_{\mathrm{T}}$ is the transformer turn ratio (Fig. 4), we have:

$$
C \frac{d V_{d c}}{d t}=\frac{1}{V_{d c}}\left(\sqrt{v_{q r}^{2}+v_{d r}^{2}} \sqrt{i_{q r}^{2}+i_{d r}^{2}}-\sqrt{v_{q s}^{2}+v_{d s}^{2}} I_{r 3}\right)
$$

If the dc-link capacitor dynamics are neglected $\left(\mathrm{V}_{\mathrm{dc}}\right.$ constant and $\mathrm{dV}_{\mathrm{dc}} / \mathrm{dt}=0$ ), then (51) reduces to the active power balance between rotor and grid side. The current amplitude $I_{r 3}$ is derived below.

\section{INTERFACE WITH THE GRID}

To complete the model of the grid connected DFIG, two more algebraic equations have to be added, namely the equations of the active and reactive power exchange between the DFIG and the grid.

\section{A. dq-to-DQ Transformation}

The grid voltages and currents are expressed with respect to the reference DQ-frame (slack bus) whereas the DFIG variables are expressed in the machine dq-frame. Thus, when writing the power equations of the grid connected DFIG, transformation from one frame to another should be applied appropriately.

Fig. 7 shows the machine dq-frame with respect to the infinite bus (slack bus) DQ-frame, where $\delta$ is the angle between the $\mathrm{q}$ - and Q-axis. It is seen that dq- and DQvariables are related by:

$$
\begin{aligned}
& v_{Q}=v_{q} \cos \delta-v_{d} \sin \delta \\
& v_{D}=v_{q} \sin \delta+v_{d} \cos \delta
\end{aligned}
$$

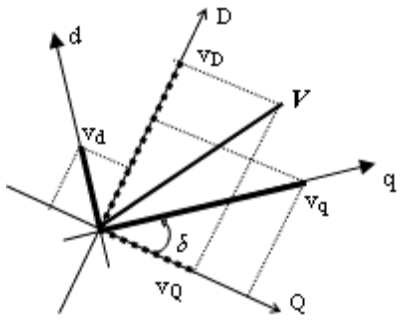

Fig. 7. Machine dq-frame with respect to slack bus DQ-frame. 


\section{B. Power Flows on the Grid Side}

In this paper, the grid is modeled by its Thevenin equivalent, i.e. an infinite bus behind a line reactance $\mathrm{X}_{\mathrm{e}}$, as depicted on Fig. 8. A stronger grid is modeled by a smaller value of $\mathrm{X}_{\mathrm{e}}$ (higher short circuit ratio), and vice versa. From Fig. 8, the powers in [pu] drawn by the grid are:

$$
\begin{aligned}
& P_{\text {tot }}=\sqrt{v_{q s}^{2}+v_{d s}^{2}} V_{b} \sin \gamma / X_{e} \\
& Q_{t o t}=\left(\left(v_{q s}^{2}+v_{d s}^{2}\right)-\sqrt{v_{q s}^{2}+v_{d s}^{2}} V_{b} \cos \gamma\right) / X_{e}
\end{aligned}
$$

where $\gamma$ is the angle between DFIG stator voltage and infinite bus voltage.

In more elaborated power system studies, the power system would be a network of several buses. In that case, the right hand side of (54) and (55) would be given by the power flow equations (PFE) at the DFIG bus.

\section{Power Flows on the DFIG Side}

Fig. 8 shows the power flows of the grid connected DFIG:

$$
\begin{aligned}
& 0=-P_{\text {tot }}+\left(P_{S}+P_{r}-P_{d c}\right) \\
& 0=-Q_{\text {tot }}+\left(Q_{S}-Q_{T}\right)
\end{aligned}
$$

where Ptot and Qtot are given in (54)-(55); $\mathrm{P}_{\mathrm{s}}$ and $\mathrm{P}_{\mathrm{r}}$ are given in (26)-(27); $\mathrm{P}_{\mathrm{dc}}$, the power flowing through the dc-capacitor during transients, is obtained by multiplying (51) by $\mathrm{V}_{\mathrm{dc}}$; $\mathrm{Q}_{\mathrm{s}}$ is the imaginary part of $\mathrm{v}_{\mathrm{qds}} . \mathrm{i}_{\mathrm{qds}}{ }^{*}$; and $\mathrm{Q}_{\mathrm{T}}$ is the reactive power consumed by the transformer, i.e:

$$
\begin{aligned}
& Q_{s}=v_{d s} i_{q s}-v_{q s} i_{d s} \\
& Q_{T}=X_{T} I_{r 3}^{2} \\
& P_{d c}=\left(\sqrt{v_{q r}^{2}+v_{d r}^{2}} \sqrt{i_{q r}^{2}+i_{d r}^{2}}-\sqrt{v_{q s}^{2}+v_{d s}^{2}} I_{r 3}\right)
\end{aligned}
$$

The current amplitude $\mathrm{I}_{\mathrm{r} 3}$ is derived below.

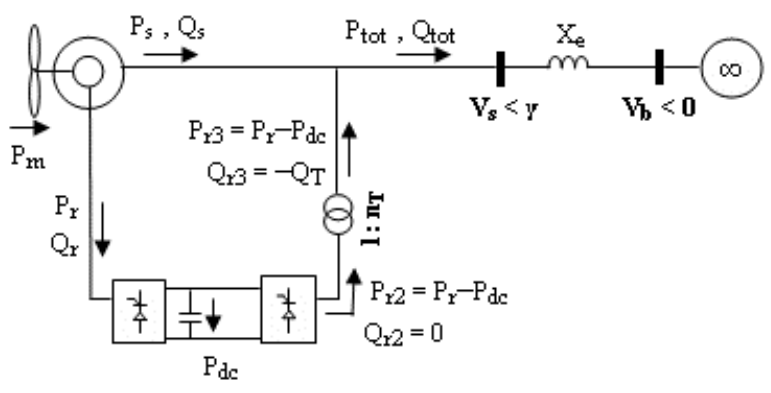

Fig. 8. Power flows of the grid connected DFIG.

\section{Current $\bar{I} r 3$}

The ac-current $\mathrm{I}_{\mathrm{r} 3} \angle \gamma_{\mathrm{Ir} 3}$ is determined by the Kirchoff current law at the connection point between grid and DFIG. From Fig. 8, this gives:

$$
\bar{I}_{r 3}=I_{r 3} \angle \gamma_{I_{r 3}}=\bar{I}_{\text {tot }}-\bar{I}_{S}
$$

where

$$
\begin{aligned}
& \bar{I}_{\text {tot }}=\left(\frac{P_{\text {tot }}+j Q_{\text {tot }}}{\sqrt{v_{q s}^{2}+v_{d s}^{2}} \cos \gamma+\sqrt{v_{q s}^{2}+v_{d s}^{2}} \sin \gamma}\right)^{*} \\
& \bar{I}_{s}=\left(i_{q s} \cos \delta-i_{d s} \sin \delta\right)+j\left(i_{d s} \cos \delta+i_{q s} \sin \delta\right)
\end{aligned}
$$

with $\mathrm{P}_{\text {tot }}$ and $\mathrm{Q}_{\text {tot }}$ given in (54)-(55). In (63) the transformation (52)-(53) was used.

\section{DAE OF THE GRID CONNECTED DFIG}

\section{A. Mathematical Background}

The mathematical model of a power system can be written as a set of differential algebraic equations (DAE):

$$
\begin{aligned}
& \frac{d x}{d t}=f(x, z, u) \\
& 0=g(x, z, u)
\end{aligned}
$$

where $\mathrm{x}, \mathrm{z}$, and $\mathrm{u}$ are the column-vectors of state variables, algebraic variables, and control inputs; $f$ and $g$ are the columnvectors of differential and algebraic equations respectively.

In transient studies, (64)-(65) are solved simultaneously. The solution gives $\mathrm{x}, \mathrm{z}$ and $\mathrm{u}$ in time domain, and allows for the calculation of system outputs:

$$
y=h(x, z, u)
$$

where $\mathrm{y}$ is the column-vector of outputs and $\mathrm{h}$ the columnvector of output algebraic equations.

In small-signal studies, (64)-(65) are linearized around an operation point and the eigenvalue analysis of the A-matrix (defined in the Appendix) allows for the assessment of the system small-signal stability.

In both studies (transient and small-signal), the first step to do is the initialization of the system. This is done in two steps. First, a loadflow is calculated on the grid side by considering the DFIG bus as a PQ or PV bus. Then, with the obtained solution, the DFIG is initialized by solving (64)-(65) with time derivative terms equal to zero and controlled outputs equal to their reference value.

\section{B. Study System DAE}

The study system is shown in Fig. 8. The reference Q-axis is aligned with the slack-bus voltage $\mathrm{V}_{\mathrm{b}} \angle 0$. Thus, if we align the machine q-axis with the stator voltage $\mathrm{V}_{\mathrm{s}} \angle \gamma$, the equations derived in the previous sections can be simplified since:

$$
v_{q s}=V_{s}
$$




$$
\begin{aligned}
& v_{d s}=0 \\
& \delta=\gamma
\end{aligned}
$$

where $\delta$ is the angle between the q-and Q-axis and $\gamma$ the angle between DFIG bus and slack bus voltages.

Table I summarizes the DAE of the different grid connected DFIG models for different set of assumptions.

TABLE I

DAE OF THE DFIG OF FIG. 8 WITH SYNCHRONOUSLY

\begin{tabular}{|c|c|c|c|}
\hline & Model A & Model B & Model C \\
\hline Assump. & $\begin{array}{c}2 \text {-mass } \\
(\mathrm{d} / \mathrm{dt})_{\text {stator }} \neq 0\end{array}$ & $\begin{array}{c}1 \text {-mass } \\
(\mathrm{d} / \mathrm{dt})_{\text {tator }} \neq 0\end{array}$ & $\begin{array}{c}1 \text {-mass } \\
(\mathrm{d} / \mathrm{dt})_{\text {stator }}=0\end{array}$ \\
\hline$f(x, x, u)$ & $\begin{array}{l}(17) \sim(20) \\
(36) \sim(38) \\
(51)\end{array}$ & $\begin{array}{l}(17) \sim(20) \\
(39) \\
(51)\end{array}$ & $\begin{array}{l}(19) \sim(20) \\
(39) \\
(51)\end{array}$ \\
\hline $\mathbf{g}(\mathbf{x}, \mathbf{x}, \mathbf{u})$ & $(56)(57)$ & $(56)(57)$ & $(56)(57)(17)(18)$ \\
\hline $\mathbf{h}(\mathbf{x}, \mathbf{x}, \mathbf{u})$ & $(21)(22)$ & (21) (22) & (21) (22) \\
\hline $\mathbf{x}$ & $\begin{array}{l}i_{q s} i_{d s} v_{q}{ }^{\prime} v_{d}{ }^{\prime} \\
\omega_{t} s \theta_{t} \\
V_{d c}\end{array}$ & $\begin{array}{l}i_{q s} i_{d s} v_{q}{ }^{\prime} v_{d}{ }^{\prime} \\
s \\
V_{d c}\end{array}$ & $\begin{array}{l}v_{q}^{\prime} v_{d}{ }^{\prime} \\
\omega_{t} s \theta_{t} \\
v_{d c}\end{array}$ \\
\hline$\underline{\mathbf{x}}$ & $\mathrm{v}_{\alpha} \gamma$ & $\mathrm{v}_{Q Y} \gamma$ & $v_{q s} \gamma i_{q s} i_{d s}$ \\
\hline$\underline{\mathbf{u}}$ & $\mathrm{v}_{\text {TT }} \mathrm{v}_{\mathrm{II}}$ & $v_{\text {II }} v_{\text {II }}$ & $v_{\text {TI }} v_{\text {II }}$ \\
\hline y & $\mathrm{i}_{\text {TT }} \mathrm{i}_{\text {it }}$ & $\mathrm{i}_{\text {T }} \mathrm{i}_{\text {it }}$ & $i_{\text {T }} i_{\text {it }}$ \\
\hline
\end{tabular}
ROTATING dq-FRAME ALIGNED with STATOR VOLTAGE

For dynamical simulations in the time domain, system and control input models have to be added to the DAE of Table I. Here, the system input is the mechanical torque $T_{m}$ (which depends on both wind speed and turbine characteristic) and the control inputs are the rotor voltages $\mathrm{v}_{\mathrm{qr}}$ and $\mathrm{v}_{\mathrm{dr}}$ (which depend on DFIG control model). Depending on the application (e.g. transient fault analysis), the time-response comparison will indicate which DFIG model to choose (i.e. which assumptions to consider as acceptable).

\section{Study System Initialization}

If voltage control is provided, the DFIG bus is a PV bus, i.e. $\mathrm{P}_{\text {tot }}$ and $\mathrm{V}_{\mathrm{s}}$ are specified to the grid and the loadflow solution gives $\mathrm{Q}_{\mathrm{tot}}$ and $\gamma$. For the study system of Fig.8, the loadflow equations are simply (54)-(55).

Since the DFIG speed is controlled, the slip s is a controlled output. Thus in steady-state it is equal to its reference value:

$$
s_{0}=s^{*}
$$

The set point $\mathrm{s}^{*}$ depends on the specified power output $\mathrm{P}_{\text {tot }}$ as follow: if $\mathrm{P}_{\text {tot }}$ is the nominal DFIG power, the speed is equal to the nominal speed; if $P_{\text {tot }}$ is less than the nominal DFIG power, the speed is equal to an optimal value, which depends on the performance characteristic of the turbine $\mathrm{C}_{\mathrm{p}}$, so that the maximum amount of wind power is extracted; i.e.:

$$
s^{*}=\left\{\begin{array}{lll}
s_{\text {nom }} & \text { if } & P_{\text {tot }}=P_{\text {nom }} \\
s\left(C_{p}\right) & \text { if } & P_{\text {tot }}<P_{\text {nom }}
\end{array}\right.
$$

In addition, as the grid-side converter controls the dc-link voltage, $\mathrm{V}_{\mathrm{dc}}$ is also a controlled output, thus:

$$
V_{d c 0}=V_{d c}^{*}
$$

where $\mathrm{V}_{\mathrm{dc}}$ * is a constant and is given by:

$$
V_{d c}^{*}=\frac{V_{r, r e f}}{m_{1}, r e f}
$$

In (73), $\mathrm{m}_{1, \text { ref }}$ is the rotor-side converter modulation index corresponding to the rotor voltage $\mathrm{V}_{\mathrm{r} \text {,ref }}[\mathrm{pu}]$ in the reference case (design choice). E.g., to allow enough variation margin, we can choose $\mathrm{m}_{1, \text { ref }}=0.75$ for $\mathrm{V}_{\mathrm{r} \text {,ref }}=\mathrm{V}_{\mathrm{s}, \text { rated }} / \mathrm{n}$ where $\mathrm{V}_{\mathrm{s} \text {,rated }}$ is the DFIG stator rated voltage and $\mathrm{n}$ the DFIG stator-rotor turn ratio.

The remaining 8 variables $\left(\mathrm{i}_{\mathrm{qs} 0}, \mathrm{i}_{\mathrm{ds} 0}, \mathrm{v}_{\mathrm{q} 0}, \mathrm{v}_{\mathrm{d} 0}, \omega_{\mathrm{t} 0}, \theta_{\mathrm{tw} 0}, \mathrm{v}_{\mathrm{qr} 0}\right.$ and $\left.\mathrm{v}_{\mathrm{dr} 0}\right)$ are determined by solving $\mathrm{f}$ and $\mathrm{g}$ simultaneously with zero time derivative terms, controlled outputs as defined above and loadflow solution as obtained above. Since the models of Table I only differ dynamically, their initial operating points $\left(\mathrm{x}_{0}, \mathrm{Z}_{0}, \mathrm{u}_{0}\right)$ are identical.

For the parameters given in the Appendix, Table II shows some steady-state values corresponding to $\mathrm{P}_{\text {tot }}=1[\mathrm{pu}], \mathrm{V}_{\mathrm{s}}=$ $1[\mathrm{pu}]$, and $\mathrm{s}_{\mathrm{nom}}=-0.03[\mathrm{pu}]$.

TABLE II

INITIAL VALUES FOR THE DFIG OF FIG. 8

WITH $\mathrm{P}_{\mathrm{TOT}}=1[\mathrm{PU}], \mathrm{V}_{\mathrm{S}}=1[\mathrm{PU}], \mathrm{S}_{\mathrm{NOM}}=-0.03$

\begin{tabular}{|r|c|c|cc|c|c|c|}
\hline & $\mathbf{V}_{\mathbf{5 0}}$ & $\mathbf{I}_{\mathbf{5 0}}$ & $\mathbf{V}_{\mathbf{I} \mathbf{0}}$ & $\mathbf{S}_{\mathbf{4} 0}$ & $\mathbf{P}_{\text {tot0 }}$ & $\mathbf{Q}_{\text {totit }}$ & $\mathbf{T}_{\mathbf{m 0}}$ \\
\hline $\mathbf{S G}$ & 1 & 0.9771 & 0.0255 & 1.0882 & 1 & 0.0113 & 0.9818 \\
\hline $\mathbf{W G}$ & 1 & 0.9843 & 0.0258 & 1.1361 & 1 & 0.114 & 0.9776 \\
\hline
\end{tabular}

$\mathrm{SG}=$ strong grid $\left(\mathrm{X}_{\mathrm{e}} / \mathrm{X}_{\mathrm{m}}=0.01\right), \mathrm{WG}=$ weak grid $\left(\mathrm{X}_{\mathrm{e}} / \mathrm{X}_{\mathrm{m}}=0.1\right), \mathrm{V}_{\mathrm{s} 0}=\mathrm{Iv} \mathrm{sqd0}, \mathrm{I}_{\mathrm{s} 0}=$ $\mathrm{l}_{\mathrm{sqd} 0} l, \mathrm{~V}_{\mathrm{r} 0}=\mathrm{I}_{\mathrm{rqd} 0} \mathrm{l}, \mathrm{I}_{\mathrm{r} 0}=\mathrm{li}_{\mathrm{rqd} 0} l, \mathrm{P}_{\text {tot } 0}$ and $\mathrm{Q}_{\mathrm{tot} 0}=$ total active and reactive power delivered to the grid, $\mathrm{T}_{\mathrm{m} 0}=$ input mechanical torque.

It is seen that for a weaker grid the reactive power required from the DFIG is substantially larger.

\section{SMALL-Signal ANALYsis}

\section{A. Eigenvalues}

For the models of Table I, Table III-V show the eigenvalues of their state matrix (see Appendix (A-2)) for the parameters given in the Appendix with $\mathrm{X}_{\mathrm{e}} / \mathrm{X}_{\mathrm{m}}=0.01$ (stronger grid). In these tables $\lambda=\sigma \pm j \omega$ are the eigenvalues, $\xi=-$ $\sigma / \operatorname{sqrt}\left(\sigma^{2}+\omega^{2}\right)$ are the mode damping coefficients, and $\mathrm{f}_{\mathrm{osc}}=$ $\omega /(2 \pi)$ are the mode oscillation frequency.

It is seen that all eigenvalues have real negative parts, thus the system of Fig. 8 is small-signal stable. In Table III, it is seen that the DFIG model with 2-mass drive train and with stator transient, presents three oscillating modes which are high $(51.2 \mathrm{~Hz})$, middle $(14.9 \mathrm{~Hz})$ and low frequent $(2.8 \mathrm{~Hz})$. Comparing Table III and IV shows that in the DFIG model with one-mass drive train, the middle frequent oscillating mode $(14.9 \mathrm{~Hz})$ disappears. Comparing Table IV and V shows that in the DFIG model without stator transients, the high frequent oscillating mode $(51.2 \mathrm{~Hz})$ disappears. 
Table VI shows the eigenvalues of the DFIG model with 2mass drive train and with stator transient for $\mathrm{X}_{\mathrm{e}} / \mathrm{X}_{\mathrm{m}}=0.1$ (weaker grid). Comparing Table III and VI shows that in a weaker grid the high frequent mode frequency increases (from $51.2 \mathrm{~Hz}$ to $57.4 \mathrm{~Hz}$ ).

TABLE III

EIGENVALUES OF MODEL A wITH Xe/Xm=0.01

\begin{tabular}{|c|c|c|c|c|}
\hline A-SG & б & () & $\xi$ & $\mathbf{f}_{\text {osc }}[\mathrm{Hz}]$ \\
\hline 2.1 & -27.13 & & 1 & 0 \\
\hline $2,2,23$ & -29.53 & 321.73 & 0.091 & 51.2 \\
\hline 24,25 & -10.76 & 93.66 & 0.114 & 14.9 \\
\hline 26,27 & -6.68 & 17.37 & 0.359 & 2.8 \\
\hline 28 & -27.01 & & 1 & 0 \\
\hline
\end{tabular}

TABLE IV

EIGENVALUES OF MODEL B WITH Xe/Xm=0.01

\begin{tabular}{|c|c|c|c|c|}
\hline B - SG & $\boldsymbol{\sigma}$ & () & $\xi$ & $f_{\text {osc }}[\mathrm{Hz}]$ \\
\hline 21 & -27.13 & & 1 & 0 \\
\hline $2.2,23$ & -28.86 & 321.74 & 0.089 & 51.2 \\
\hline 24,25 & -16.82 & 24.32 & 0.569 & 3.9 \\
\hline 26 & -25.93 & & 1 & 0 \\
\hline
\end{tabular}

TABLE V

EIGENVALUES OF MODEL C WITH Xe/Xm=0.01

\begin{tabular}{|r|c|c|c|c|}
\hline $\mathbf{C}-\mathbf{S G}$ & $\boldsymbol{\sigma}$ & $\boldsymbol{\omega}$ & $\boldsymbol{\xi}$ & $\mathbf{f}_{\mathbf{0 s c}}[\mathbf{H z}]$ \\
\hline $\mathbf{h l}$ & -27.13 & & 1 & 0 \\
\hline $\mathbf{2 . 2} \mathbf{h 3}$ & -16.59 & 23.15 & 0.582 & 3.7 \\
$\mathbf{h A}$ & -28.62 & & 1 & 0 \\
\hline
\end{tabular}

Since the maximum oscillation frequency indicates the minimum simulation time step (STS) to use for the DFIG, it is seen from Table III-V that the STS of the DFIG with 1-mass drive train should be the same as that of the model with 2mass drive train, whereas the STS of the DFIG model without stator transients can be significantly larger than that with stator transients. From Table VI, it is also seen that when stator transients are represented, the STS should be smaller for a weaker the grid.

TABLE VI

EIGENVALUES OF MODEL A WITH Xe/Xm=0.1

\begin{tabular}{|c|c|c|c|c|}
\hline A - WG & $\sigma$ & (1) & $\xi$ & $\mathbf{f}_{\text {osc }}[\mathrm{Hz}]$ \\
\hline 21 & -39.29 & & 1 & 0 \\
\hline $2.2,2.3$ & -19.15 & 360.17 & 0.053 & 57.4 \\
\hline 24,25 & -11.79 & 93.72 & 0.125 & 14.9 \\
\hline $26,2.7$ & -7 & 17.61 & 0.369 & 2.8 \\
\hline 28 & -20.77 & & 1 & 0 \\
\hline
\end{tabular}

\section{B. Participation factors}

Participation factors are calculated with the system matrix and its right and left eigenvectors (see Appendix (A-5)). These factors indicate the normalized contribution of each state variable in the different natural modes of the system.

Table VII shows the result for the DFIG with 2-mass drive train and with stator transient (Model A of Table I). From the columns of Table VII, it is seen that:
- The decaying mode $\lambda_{1}$ is associated with none of the ac state variables, but only with the dc state variable $\mathrm{V}_{\mathrm{dc}}$.

- The fast oscillating mode $\left(\lambda_{1}, \lambda_{2}\right)$ is mainly associated with stator transients $\left(i_{\mathrm{qs}}, i_{\mathrm{ds}}\right)$.

- The middle and low frequent oscillating modes $\left(\lambda_{3}, \lambda_{4}\right)$ and $\left(\lambda_{5}, \lambda_{6}\right)$ are mainly associated with drive train transients $\left(\omega_{\mathrm{t}}, \mathrm{s}, \theta_{\mathrm{tw}}\right)$ and rotor flux q-component transients $\left(\mathrm{v}_{\mathrm{d}}\right.$ ' is proportional to $\psi_{\mathrm{qr}}$, see (14)).

- The decaying mode $\lambda_{8}$ is mainly associated with rotor flux d-component transients $\left(\mathrm{v}_{\mathrm{q}}\right.$ ' is proportional to $\psi_{\mathrm{dr}}$, see (13)).

TABLE VII

PARTICIPATION FACTORS OF MODEL A WITH A STRONG GRID (Xe/Xm=0.01)

\begin{tabular}{|c|c|c|c|c|c|c|c|c|}
\hline 0 & 0.470 & 0.470 & 0.030 & 0.030 & 0.007 & 0.007 & 0.010 & $x l=i_{15}$ \\
\hline 0 & 0.442 & 0.442 & 0.016 & 0.016 & 0.004 & 0.004 & 0.006 & $x 2=i_{i d s}$ \\
\hline 0 & 0.036 & 0.036 & 0.007 & 0.007 & 0.018 & 0.018 & 0.900 & $\mathbf{x} \mathbf{3}=\mathbf{v}_{\mathrm{q}}$, \\
\hline 0 & 0.050 & 0.050 & 0.313 & 0.313 & 0.204 & 0.204 & 0.052 & $x_{4}=v_{d}$ \\
\hline 0 & 0 & 0 & 0.010 & 0.010 & 0.440 & 0.440 & 0.009 & $x^{5}=\omega_{t}$ \\
\hline 0 & 0.002 & 0.002 & 0.446 & 0.446 & 0.032 & 0.032 & 0.009 & $x 6=s$ \\
\hline 0 & 0 & 0 & 0.178 & 0.178 & 0.295 & 0.295 & 0.014 & $\mathbf{x} 7=\theta_{\mathrm{tw}}$ \\
\hline 1 & 0 & 0 & 0 & 0 & 0 & 0 & 0 & $x_{8}=V_{d c}$ \\
\hline$\lambda 1$ & 2.2 & 23 & 24 & 25 & 26 & 27 & 28 & \\
\hline
\end{tabular}

\section{CONCLUSION}

In this paper, different models of the grid connected DFIG were considered (one- or two-mass drive train, with or without stator transients). For each of them, the non-linear differential algebraic equations were established and the initialization of the system was presented. The models were compared with each other with the eigenvalue analysis of their small-signal model.

The main conclusions were that the DFIG model with stator transients and 2-mass drive train presents three oscillating modes (fast, middle and low frequent oscillations of $\sim 50 \mathrm{~Hz}$, $\sim 15 \mathrm{~Hz}$ and $\sim 3 \mathrm{~Hz}$ respectively); dc-link voltage and rotor flux d-component are responsible for decaying modes; stator current, turbine speed, twist angle, generator speed and rotor flux q-component are responsible for oscillating modes; and there is a minimum grid strength under which the DFIG operation is not possible.

\section{APPENDIX}

\section{A. System Parameters}

DFIG parameters are not readily available, thus in this paper they were defined in terms of ratios. 


\begin{tabular}{|l|r|l|}
\hline \multicolumn{3}{|c|}{ System Constants } \\
\hline$\omega s$ & 1 & {$[\mathrm{pu}]$} \\
\hline$\omega \mathrm{B}$ & $2 \pi^{*} 50$ & $\mathrm{rad} / \mathrm{sec}$ \\
\hline $\mathrm{Vb}$ & 1 & {$[\mathrm{pu}]$} \\
\hline
\end{tabular}

\begin{tabular}{|l|r|}
\hline \multicolumn{2}{|c|}{ System Inqut } \\
\hline $\operatorname{Tm}$ & $1[\mathrm{pu}]$ \\
\hline
\end{tabular}

\begin{tabular}{|c|c|c|}
\hline \multicolumn{3}{|c|}{ Drive Train } \\
\hline $\mathrm{Ht}$ & & [sec] \\
\hline $\mathrm{Hg}$ & 0.5 & [sec] \\
\hline Htot & 3.5 & [sec] \\
\hline $\mathrm{K}$ & 10 & [pu/rad] \\
\hline $\mathrm{D}$ & 0.01 & [pu*sec/rad] \\
\hline
\end{tabular}

\begin{tabular}{|c|c|c|}
\hline \multicolumn{2}{|r|}{ DFIG } & \\
\hline Rs & 0.005 [pu] & \\
\hline $\mathrm{Rr}$ & $1.1 * \mathrm{Rs}$ [pu] & \\
\hline $\mathrm{Xm}$ & $450 * \mathrm{Rs}$ [pu] & \\
\hline Lm & $\mathrm{X}+\mathrm{w} / \omega \mathrm{s}$ [pu] & \\
\hline Lss & $1.01 * \operatorname{Lm}$ [pu] & \\
\hline Lrr & $1.005 * \mathrm{Ls}$ [pu] & \\
\hline $\mathrm{n}$ & $1.5[-]$ & \\
\hline \multicolumn{3}{|c|}{ Back-to-back converter } \\
\hline $\mathrm{x}_{\mathrm{T}}$ & \begin{tabular}{l|l}
0.5 & [pu] \\
\end{tabular} & \\
\hline $\mathrm{C}$ & 0.0001 [pu] & \\
\hline \multicolumn{3}{|c|}{ Grid } \\
\hline \multirow{2}{*}{$\mathrm{X}_{\mathrm{e}} / \mathrm{X}_{\mathrm{m}}$} & 0.01 [pu] & for strong grid \\
\hline & 0.1 [pu] & for weak grid \\
\hline
\end{tabular}

\section{B. Linearization and State Matrix}

The linearization of (64)-(65) is done by a Taylor series expansion around the operating point $\left(\mathrm{x}_{0}, \mathrm{z}_{0}, \mathrm{u}_{0}\right)$ calculated by the system initialization described above. Neglecting terms of order 2 and above, the corresponding linear model is:

$$
\frac{d}{d t} \Delta x=A \cdot \Delta x+B \cdot \Delta u
$$

where

$$
\begin{aligned}
& A=\left[\frac{\partial f}{\partial x}-\frac{\partial f}{\partial z}\left(\frac{\partial g}{\partial z}\right)^{-1} \frac{\partial g}{\partial x}\right]_{x_{0}, z_{0}, u_{0}} \\
& B=\left[\frac{\partial f}{\partial u}-\frac{\partial f}{\partial z}\left(\frac{\partial g}{\partial z}\right)^{-1} \frac{\partial g}{\partial u}\right]_{x_{0}, z_{0}, u_{0}}
\end{aligned}
$$

The matrix A is the system state matrix. Its eigenvalues (real and/or complex) give the natural modes of the system and allow for the assessment of the small-signal stability. If $\mathrm{A}$ is real, complex eigenvalues always appear in conjugate pairs.

\section{Participation factors}

The participation factors of mode $i$, are given by [8]:

$$
\boldsymbol{p}_{\boldsymbol{i}}=\left[\begin{array}{c}
p_{1 i} \\
p_{2 i} \\
\ldots \\
p_{m i}
\end{array}\right]
$$

where

$$
p_{k i}=\frac{\left|\Phi_{k i}\right|\left|\Psi_{i k}\right|}{\sum_{k=1}^{n} \mid \Phi_{k i} \|}
$$

In (A-4) and (A-5), $\mathrm{m}$ is the number of state variables, $\mathrm{p}_{\mathrm{ki}}$ the participation factor of the $\mathrm{k}^{\text {th }}$ state variable into mode $\mathrm{i}, \Phi_{\mathrm{ik}}$ the $\mathrm{i}^{\text {th }}$ element of the $\mathrm{k}^{\text {th }}$ right-eigenvector of $\mathrm{A}, \Psi_{\mathrm{im}}$ the $\mathrm{m}^{\text {th }}$ element of the $i^{\text {th }}$ left-eigenvector of $\mathrm{A}$.

\section{REFERENCES}

[1] J.B. Ekanayake, L. Holdsworth, XG. Wu, N. Jenkins, "Dynamic modelling of doubly fed induction generator wind turbines," IEEE Trans. on Power Sytstems, vol. 18, pp.803-809, May 2003.

[2] V. Akhmatov, "Modelling of Variable-Speed Wind Turbines with DoublyFed Induction Generator in Short-Term Stability Investigations," $3^{\text {rd }}$ Int. Workshop on Transmission Networks for Offshore Wind Farms, Stockholm Sweden, Apr. 2002.

[3] J.G. Slootweg, H. Polinder, W.L. Kling, "Dynamic modelling of a wind turbine with doubly-fed induction generator," in Proc. 2001 IEEE Power Eng. Soc. Summer Meeting, vol. 1, pp 644-649.

[4] S.A. Papathanassiou, M.P. Papadopulos, "State-space modelling and eigenvalue analysis of the slip energy recovery drive," in IEE Proc. Jan. 1997 - Electr. Power Appl., vol. 144, , pp. 27-36.

[5] R. Pena, J.C. Clare, G.M. Asher, "Doubly fed induction generator using back-to-back PWM converters and its application to variable-speed windenergy generation," in IEE Proc. May 1996 - Electr. Power Appl., vol. 143, No. 3, May 1996.

[6] N. Mohan, Power Electronics, $3^{\text {rd }}$ ed., John Wiley \& Sons, 2003, p. 228.

[7] D.W. Novotny, T.A. Lipo, Vector Control and Dynamics of AC Drives, Oxford Science Publications, 1998.

[8] P. S. Sauer, M. A. Pai, Power System Dynamics and Stability, PrenticeHall 1998.

[9] P. Kundur, Power System Stability and Control, Mc Graw Hill 1994.

[10] IEEE committee report, "Recommended phasor diagram for synchronous machines," IEEE Transactions on Power Apparatus and Systems, Vol. PAS-88, No. 11, November 1969.

\section{BIOGRAPHIES}

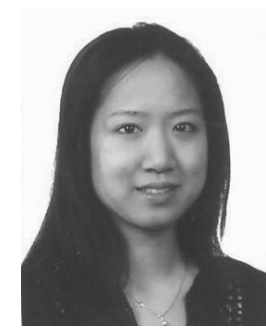

Francoise Mei was born in Ottignies-Louvain-laNeuve, Belgium, on September 3, 1981. She studied electro-mechanical engineering at the Catholic University of Leuven (K.U.Leuven, Belgium) and graduated in July 2004. She is now working on her Ph.D. at Imperial College London. Her special fields of interest include distributed generation modelling and control.

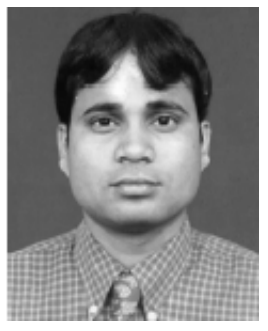

Bikash C. Pal (M'00-SM' 02) received the B.E.E. (Hons.) degree from Jadavpur University, Calcutta, India, and the M.E. degree from the Indian Institute of Science, Bangalore, India, in 1990 and 1992, respectively. He received the Ph.D. degree from Imperial College London, London, U.K., in 1999. He is presently a Lecturer in the Department of Electrical and Electronic Engineering, Imperial College London. His research interests are in the area of power system dynamics and FACTS controllers. 